Orijinal araştırma-Original research

\title{
İdiopatik skolyozda hibrid posterior enstrümentasyonun etkinliği ve güvenilirliliği
}

\author{
The efficacy and safety of hibrid posterior instrumentation in idiopathic \\ scoliosis
}

\author{
Utku Demir, Gündüz Tezeren, Seyran Kılınç*, Okay Bulut, Hayati Öztürk, \\ Zekeriya Öztemur
}

Ortopedi ve Travmatoloji Kliniği (Dr. U. Demir) Sivas Numune Hastanesi, TR-58040 Sivas, Ortopedi ve Travmatoloji Anabilim Dalı (Prof. Dr. G. Tezeren, Yrd. Doç. Dr. S. Kılınç, Prof. Dr. O. Bulut, Doç. Dr. H. Öztürk, Doç. Dr. Z. Öztemur,) Cumhuriyet Üniversitesi Tıp Fakültesi, TR58140 Sivas.

\section{Özet}

Amaç. Biz bu çalışmada skolyoz deformiteli hastalarımızda uyguladığımız cerrahi tedavilerin sonuçlarını retrospektif olarak değerlendirmeyi amaçladık. Yöntem. 2002-2010 yılları arasında kliniğimizde 21 olguya cerrahi tedavi uygulanmış olup bunlardan 13 idiopatik skolyozlu olgu kriterlere uygun bulunup çalışma kapsamına alınmıştır. Bulgular. Tüm olgulara hibrid sistem (üst torakal bölgeye çengel, lomber bölgeye poliaksiyel transpediküler vida kombinasyonu) titanyum posterior enstrümentasyon uygulanmıştır. Ek olarak tüm olgulara otolog greftler ile füzyon yapılmıştır. Ortalama takip süresi 49,7 aydır (14-92 ay). Ortalama Cobb açısı preoperatif $47^{\circ}$, postoperatif $19,4^{\circ}$, son kontrolde $25^{\circ}$ idi. Sonuç. Hibrid sistem posterior enstrümentasyon uyguladığımız idiopatik skolyozun cerrahi tedavisi etkin ve güvenilir bulunmuştur.

Anahtar sözcükler: İdiyopatik skolyoz, hibrid sistem, posterior enstrümantasyon

\begin{abstract}
Aim. In this study, we aimed to evaluate retrospectively results of surgical treatment of scoliosis deformity in our patients. Method. In our clinic 20 cases underwent posterior instrumentation and fusion. Of them, 13 patient were included in the study. Results. All cases underwent hybrid system instrumentation (upper hooks and lower polyaxial transpedicle screws), with titanium implants and fusion with autologous grafts.Mean follow-up was 49.7 months (range 14-92). Mean cobb angle was $47^{\circ}$ preoperatively, $19.4^{\circ}$ postoperatively, $25^{\circ}$ at last follow-up. Conclusion. Hybrid system posterior instrumentation was safe and effective method in the surgical treatment of idiopathic scoliosis.
\end{abstract}

Keywords: Idiopathic scoliosis, hybrid system, posterior instrumentation.

Geliş tarihi/Received: 27 Haziran 2014; Kabul tarihi/Accepted: 15 A ğustos 2014

*İletişim adresi:

Dr. Seyran Kılınç, Ortopedşi ve Travmatoloji Anabilim Dalı, Cumhuriyet Üniversitesi Tıp Fakültesi, TR-58140 Sivas. E-posta: seyrankilinc@ hotmail.com

\section{Giriş}

Skolyoz, omurganın en yaygın deformitesidir. Ayakta çekilen direkt grafilerde, frontal planda 10 derece ve üzerindeki lateral eğrilikler skolyoz olarak tanımlanmaktadır. Skolyozda deformite sadace frontal planla sinırlı kalmamakta, sagittal ve aksiyel planları da içine alan üç boyutlu bir deformite ortaya çıkmaktadır. Frontal planda laterale kayma, aksiyel planda rotasyon ve sagittal planda lordoza neden olan intervertebral ekstansiyon görülmektedir [1]. İdiyopatik skolyoz yapısal nedenli skolyozların yaklaşık \%80'ini oluşturmakta olup deformitenin nedeni bilinmemektedir. İdiyopatik skolyozun tanıs1, iyi bir fizik muayene ile nörolojik nedenler ve diğer belirtilerin (örneğin, nörofibromatoziste cilt lekeleri gibi) tespit edilmemesi, radyolojik muayene ile de doğumsal anomalilerin ekarte edilmesi ile konulabilir [1,2]. 
İdiyopatik skolyoz büyüme çağında herhangi bir yaşta ortaya çıkabilir. Ortaya çıkışı bakımından üç zaman diliminde zirve yapar. Yaşamın ilk senesi, 5 ile 6 yaşları arası ve 11 yaşından iskelet gelişiminin tamalanmasına kadar geçen süreç en sık karşılaşılan zaman dilimleridir. Bu şekilde idiyopatik skolyoz, deformitenin başladığı yaşa göre üç gruba ayrılır [1, 2], 1980'li yıllarda skolyotik deformitenin üç boyutlu olduğunun anlaşılması üzerine frontal, sagittal ve aksiyel planlarda düzeltmeye olanak sağlayan üçüncü nesil enstrümantasyon sistemleri (Cotrel-Dubousset, TSRH, Isola, Alıcı) geliştirilmiştir $[1,3,4]$. Bu sistemler ile, posterior elemanlarının her iki tarafına yerleştirilen çubukların birden fazla çengel ve vidalar ile omurgaya tespit edilmesi ile daha iyi bir düzeltme imkanı elde edilmiş ve eksternal tespit ihtiyacını ortadan kaldıracak kadar güçlü bir internal tespit sağlanmıştır [4].

$\mathrm{Bu}$ çalışmanın amac1, kliniğimizde posterior hibrit enstrümantasyon ile tedavi edilen idiyopatik skolyozlu olguların sonuçlarını klinik ve radyolojik olarak değerlendirilmek ve sonuçlarını tartışmaktır.

\section{Gereç ve yöntem}

Cumhuriyet Üniversitesi Tıp Fakültesi Eğitim ve Araştırma Hastanesi Ortopedi ve Travmatoloji Kliniği'nde 2002-2010 tarihleri arasında skolyoz deformitesi konulmuş ve cerrahi uygulanmış 21 hastadan son kontrole gelen, yeterli takip ve dökümantasyona sahip 13 idiopatik skolyozlu hasta çalışmaya dahil edilmiştir. Bu çalışmanın yapılması, Cumhuriyet Üniveristesi Bilimsel Araştırmaları Değerlendirme Kurulu tarafindan 29.09.2010 tarihli ve 2010-06/23 karar numaralı tutanakla uygun bulunmuştur. Bu hastaların ameliyat öncesi, ameliyattan hemen sonra ve son kontrollerinde elde edilen klinik ve radyolojik muayene sonuçları retrospektif olarak değerlendirilmiştir.

Radyolojik muayenede ameliyat öncesi, ameliyat sonrası ve son kontrollerinde ayakta ön, arka ve yan grafiler büyük kasete çektirilmiştir. Bu grafilerde; proksimal torasik, torakal, lomber bölgedeki üst ve alt son vertebraları, apikal, nötral ve stabil vertebraları belirlenmiş ve Cobb yöntemi ile eğriliklerin büyüklüğ̈̈ ölçülmüştür. Ameliyat öncesinde eğrilikler King sınıflama sistemine göre tiplendirilmiştir. Ameliyat sonrası erken dönemde çekilen ön-arka grafilerde, aynı seviyelerden Cobb açıları ölçülmüştür (Resim 1).

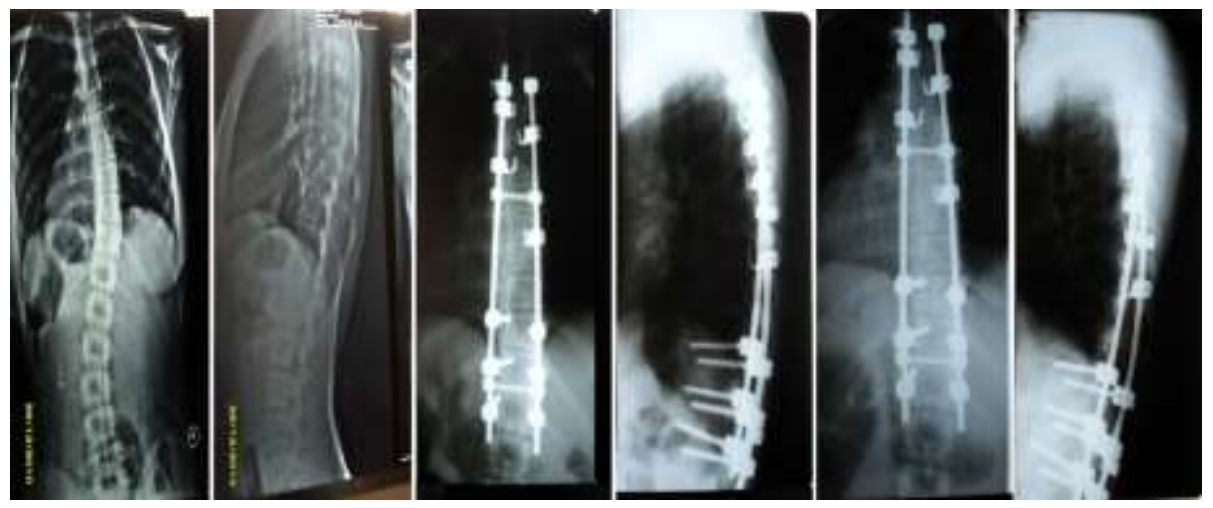

Resim 1. On iki yaşındaki kadın hastamızın ameliyat öncesi, sonrası ve son kontroldeki önarka grafileri.

Vakaların hepsinde ana şikayet sırtta deformite idi. Kliniğimize başvurduklarında cerrahi sınırlar içerisinde bulunup opere edilmişlerdir. Tüm olgulara posterior girişimle enstrümantasyon yapılarak tedavi edilmişlerdir. Dört olguda anterior girişim ile gevşetme ve torakoplasti prosedüre eklenmiştir. Çalışmaya dahil edilmiş opere edilmiş hastalarda hibrit sistem kullanılmıştır. Torakal bölgelerine genellikle çengel, lumbal bölgelerine poliaksiyel pedikül vidası kullanılmıştır. İnsizyon orta hattan yapılmış transvers çıkıntılara kadar subperiostal olarak ulaşılmıştır. Faset eklemlerin kapsülü, interspinöz ve supraspinöz ligamentler dahil tüm yumuşak dokular temizlenmiştir. 
Olgularımızın tamamına, titanyum posterior spinal enstrümantasyon uygulanmıştır. Posterior iliak kanattan alınan otogreftle greftleme işlemi gerçekleştirilmiştir. Omurgaya tespit için çengel ve poliaksiyel vidalar, uygun eğim verdiğimiz bir çift rot ve rotları birbirine bağlayan transvers bağlayıcılar kullanılmıştır. Füzyona dahil edilen vertebralar proksimalde T2, distalde L5 arasında olup en uzun füzyon seviyesi T2, L4 arasında olmuştur. Füzyona dahil edilen vertebra seviyeleri 6 ile 14 seviye arasında değişmekle beraber ortalama 10,3 olarak bulunmuştur. Tüm vakalarda faset eksizyonu ve dekortikasyon yapılmış olup vakaların hepsinde posterior ilyak kanattan alınan otogreft ile greftleme işlemi gerçekleştirilmiştir.

Ameliyatlarda $250 \mathrm{cc}$ ile $1000 \mathrm{cc}$ arasında ortalama $673 \mathrm{cc}$ kan transfüzyonu (eritrosit süspansiyonu) kullanılmıştır.

Hastalara ameliyattan yarım saat önce proflaktik olarak 1 gr sefazolin sodyum intravenöz yapılmış, antibiyotik profilaksisi ameliyat sonrası 5. güne kadar devam ettirilmiştir. Hastalar yüz üstü pozisyona çevrilmeden batın ve toraks kafesinin basıya maruz kalmaması için, orta kısım boşlukta kalacak şekilde koltuk altından pelvise kadar silikon destekler yerleştirilmiştir.

Çalışmamızın verileri SPSS $(14,0)$ programına yüklenerek değerlendirilmiştir. Hesaplamalarda Friedman ve Wilcoxon Testleri kullanılmıştır.

Sonuç olarak; çalışmayı oluşturan 13 skolyoz hastasının 9'u kız (\%69,3), 4'ü erkektir $(\% 30,7)$. Bir olgu $(\% 7,6)$ juvenil, 12 olgu $(\% 92,4)$ adölesan idiyopatik skolyoz idi. Ameliyat sırasında hastaların yaşları 8 ile 19 arasında olup ortalama 14 bulunmuştur. Cinsiyetlerine göre dağılımlarına bakıldığında kızlarda yaş aralığı 8 ile 16 arasında olduğu görülmüş, ortalama 12,8 bulunmuştur. Erkeklerde ise yaş dağılımı 15 ile 19 arasında olduğu görülmüş, ortalama 14,2 bulunmuştur. Olgular 14 ay ile 92 ay arasında takip edilmiş olup, ortalama takip süresi 49,7 aydır. Hastanede yatış süresine bakıldığında ise 12 ile 83 gün arasında bulunmuş olup, ortalama 25,3 gün hastanede yatış süresi tespit edilmiştir (Tablo 1).

Tablo1. Tüm olguların inceleme verileri.

\begin{tabular}{|c|c|c|c|c|c|c|c|c|c|c|c|c|c|}
\hline 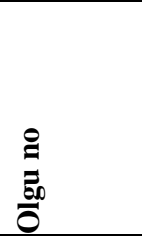 & 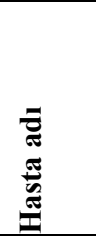 & 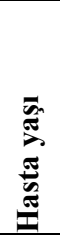 & 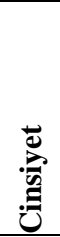 & 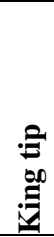 & 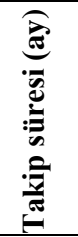 & 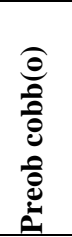 & $\begin{array}{l}\hat{0} \\
0 \\
0 \\
0 \\
0 \\
0 \\
0 \\
0 \\
0\end{array}$ & 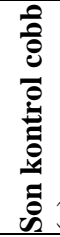 & 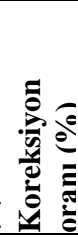 & 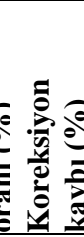 & 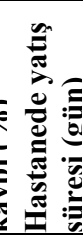 & 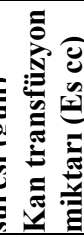 & 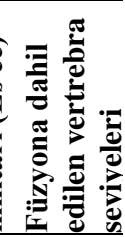 \\
\hline 1 & MB T & 13 & $\mathrm{~K}$ & 1 & 14 & 55 & 12 & 12 & 78,1 & 0 & 12 & 1000 & T11-L4 \\
\hline 2 & Fİ & 8 & K & 2 & 70 & 70 & 40 & 55 & 42,8 & 21,4 & 83 & 250 & T2-L2 \\
\hline 3 & HÖ & 11 & K & 2 & 92 & 60 & 26 & 28 & 56,6 & 3,3 & 43 & 250 & T2-L4 \\
\hline 4 & RD & 13 & K & 2 & 53 & 52 & 18 & 24 & 65,3 & 11,5 & 16 & 750 & T2-L2 \\
\hline 5 & TA & 16 & $\mathrm{~K}$ & 5 & 53 & 45 & 24 & 26 & 46,6 & 4,4 & 15 & 500 & T2-L1 \\
\hline 6 & MT Ç & 16 & $\mathrm{~K}$ & 5 & 48 & 29 & 10 & 11 & 65,5 & 3,4 & 24 & 750 & T3-L3 \\
\hline 7 & $\mathrm{AH}$ & 19 & E & 2 & 45 & 56 & 28 & 46 & 50 & 32,1 & 79 & 1000 & T5-L3 \\
\hline 8 & İY & 17 & $\mathrm{E}$ & 2 & 53 & 18 & 8 & 10 & 55,5 & 11,1 & 24 & 1000 & T2-L1 \\
\hline 9 & AE A & 16 & $\mathrm{E}$ & 2 & 30 & 20 & 4 & 6 & 80 & 10 & 40 & 1000 & T2-L4 \\
\hline 10 & ÖE & 15 & $\mathrm{E}$ & 2 & 66 & 116 & 50 & 70 & 56,8 & 17,2 & 40 & 500 & T3-L5 \\
\hline 11 & GB & 14 & $\mathrm{~K}$ & 2 & 53 & 35 & 16 & 18 & 54,2 & 5,7 & 13 & 500 & T2-L2 \\
\hline 12 & TK & 12 & $\mathrm{~K}$ & 2 & 17 & 35 & 13 & 15 & 62,8 & 5,7 & 23 & 500 & T3-T12 \\
\hline 13 & TS & 13 & $\mathrm{~K}$ & 2 & 53 & 20 & 4 & 4 & 80 & 0 & 18 & 750 & T3-L1 \\
\hline Ortalama & & 14 & & 4 & 49,7 & 47 & 19,4 & 25 & 61,1 & 9,7 & 25,3 & 673 & \\
\hline
\end{tabular}

Olguların eğrilik yönü incelendiğinde iki olgu hariç diğer tüm olgular $(\% 84,7)$ torakal eğriliğin yönünün sağa, lumbal eğriliğin yönünün sola olduğu görülmüştür. İki olguda ise $(\% 15,3)$ torakal eğriliğin sola, lumbal eğriliğin sağ tarafa olduğu Tip 2 ve Tip 4 eğrilikler tespit edilmiştir. Radyolojik değerlendirmede, eğrilik tipleri King sınıflamasına göre değerlendirilmiştir. King Tip $2 \% 69,2$ (9 hasta) ile en çok görülen tiptir. En az King Tip 1 ve Tip $4 \% 7,7$ (1'er hasta) oranında görülmüştür (Tablo 2). 
Tablo2. Olguların King sınıflamasına göre dağılımı.

\begin{tabular}{lll}
\hline Eğrilik tipi & Olgu Sayısı & Yüzdelik dağılımı (\%) \\
\hline King tip 1 & 1 & 7,7 \\
King tip 2 & 9 & 69,2 \\
King tip 3 & - & $\overline{1}$ \\
King tip 4 & 1 & 7,7 \\
King tip 5 & 2 & 15,4 \\
\hline
\end{tabular}

Ameliyat öncesinde majör eğriliklerin ayakta çekilen ön arka grafilerinde Cobb yöntemi ile ölçülen değerleri $18^{\circ}$ ile $116^{\circ}$ arasında olup ortalama $47^{\circ}$ bulunmuştur. Ameliyat sonras1 ortalama $\% 61,1$ düzeltme ile 19,40 tespit edilmiştir. Son kontrolde ise $\% 0$ ile \%21,2 arasında, ortalama \%9,7 korreksiyon kaybı görülmüştür. (Tablo 3).

Tablo 3. Hastaların preop, postop, son kontroldeki cobb açısı değerleri.

\begin{tabular}{llllll}
\hline Cobb Açısı & Olgu sayısı & Ortalama & Standart sapma & Minimum & Maksimum \\
Preoperatif & 13 & 47,000 & 26,6833 & 18,0 & 116,0 \\
Postoperatif & 13 & 19,462 & 13,8481 & 4,0 & 50,0 \\
Son Kontrol & 13 & 25,000 & 20,2443 & 4,0 & 70,0 \\
\hline $\mathbf{X}^{\mathbf{2}=25,12 ; ~ p=0,001 ; ~ p>0,05}$ & & & \\
\hline
\end{tabular}

Olgular sagital planda incelendiğinde iki olguda hiperkifoz $\left(50^{\circ}\right.$ ile $\left.85^{\circ}\right)$ görülmüş ve ameliyat sonrasında kifoz açıları normal sınırlara getirilmiştir $\left(26^{\circ}\right.$ ile $\left.35^{\circ}\right)$. Son kontrollerindeki değerlerinde $20^{\circ}$ ve $25^{\circ}$ olduğu görülmüştür.

Olguların hiçbirinde yüzeyel yada derin yara yeri enfeksiyonu tespit edilmemiştir. Takiplerinde de hiçbir olguda geç dönem derin enfeksiyon tespit edilmemiştir. Çalışmaya katılan olgularımızın hiçbirinde nörolojik defisit saptanmamıştır. Takip süreleri sonunda psödoartroz görülmemiştir. Hiçbir olguda revizyon cerrahisine gerek duyulmamıştır.

\section{Tartışma}

Adölesan idiyopatik skolyozun tedavisi ortopedik cerrahinin her zaman en zorlayıcı konularından biri olmuştur. Eğriliğin ciddiyeti, paterni ve progresyonu açısından çok geniş bir spektrumda klinik özellikler gösteren, heterojen bir hastalıktır. Tedaviye karar verilirken skolyozun tipi, büyüklüguü, esnekliği, ilerleme riski ve yaş göz önünde bulundurulmalıdır. Tedavi seçenekleri ise gözlem, konservatif tedavi yada cerrahi tedavidir $[1,3,5]$.

Cerrahi tedavi endikasyonları, genel olarak eğriliğin 45 üzerinde olması, daha küçük eğriliklerde takipler arasında progresyon gözlenmesi, ciddi bel ve sırt ağrısı, deformitenin neden olduğu kardiak, pulmoner ve psikolojik ciddi şikayetlerin varllğı olarak kabul edilmektedir [2, 5-9]. Cerrahi tedavide amaçlanan üç boyutlu deformiteyi mümkün olabildiğince düzeltebilmek, elde edilen düzelmenin korunabilmesi için füzyon sağlamak, baş ve gövdeyi pelvis üzerinde dengede tutabilmektir. Bunun içinde tedavide enstrümantasyon sistemleri kullanılmaktadır $[1,2,8,9]$.

Bir enstrümantasyon sisteminden beklenen, üç boyutlu düzeltmeye imkan vermesi, kolay uygulanabilir ve düşük maliyetli olması, ameliyat sonrası dış tespite gereksinimi ortadan kaldırmasıdır $[5,8,10]$. Posterior girişim cerrahi tedavide en sik kullanılan yöntemdir.Ayrıca anterior girişim veya anterior ve posterior kombine girişimde tercih edilebilir.Bütün eğrilik tipleri posterior girişimle tedavi edilebilir $[1,2,7,11]$.

Adölesan idiopatik skolyozda, anterior ve posterior kombine girişim,özellikle rijit torakal eğriliklerde uygulanmaktadır.İlk seferde anterior girişimle diskektomi, ikinci seferde de posterior girişimle korreksiyon, füzyon ve enstrümantasyon gerçekleştirilir [1, 2, 12].

Anterior girişimin posterior girişime tercih edilmesinin nedenleri; disk eksizyonuyla beraber anterior girişimle daha iyi düzeltme sağlanabilmesidir. Ayrıca daha az segment füzyona katılır ve distalde daha fazla hareketli segment kalır. Füzyon seviyesi lomber 
omurgada ne kadar ilerletilirse, uzun süreli takiplerinde takiplerinde bel ağrisı şikayetinin daha fazla olduğu bulunmuştur [11-14], 12 yaş altında cerrahi tedavi kararı alınan çocuklardada ileride gelişebilecek krankşaft deformitesinin önlenebilmesi amacı ile anterior füzyonun eklenmesi önerilmiştir $[15,16]$.

Çalışmaya dahil ettiğimiz vakalardan beş tanesinde ilk seansta anterior girişimle diskektomi yapılıp ikinci seansta posterior girişimle enstrümantasyon uygulanmıştır. Çalışmadaki olguların cinsiyet dağılımına bakıldığında \%69,2 kız, \%30,8 erkek bulunmuştur. Ortalama ameliyat yaşı ise 14 olarak bulunmuştur. Literatüre bakıldığında, özellikle cerrahi tedavi gerektiren eğriliklerin kızlarda görülme oranı, erkeklere göre anlamlı derecede yüksektir. Bjerkreim ve ark. [17] cerrahi tedavi gerektiren adölesan idiyopatik skolyoz olgularının \%76'sının kız, \%24'ünün erkek olduğunu ve ameliyat esnasında ortalama yaşı 16,8 olarak bildirmiştir. Sucato ve ark [18]'nın yaptıkları bir çalışmada, cerrahi tedavi edilen adölesan idiyopatik skolyozlu hastaların, cinsiyet ve yaş dağılımları incelenmiştir. Buna göre, erkeklerde semptomların başlangıç yaşı, gerekse de ameliyat esnasındaki yaşları kızlara göre anlamlı olarak büyük bulunmuştur. Benli ve ark. [19] \%58,7 kız ve \%41,3 erkek oranı ile ortalama yaşı 14,4 olarak bildirmiştir.

Literatürde, cerrahi tedavi kararı verilen eğriliklerin sıklı̆̆ 1 değerlendirildiğinde, King sınıflamasına göre, Tip 2 ve Tip 3 en fazla görüldüğü bildirilmiştir [20]. Bizim çalışmamızda King sınıflamasına göre en sık; Tip $2(\% 69,2)$, Tip $5(\% 15,4)$ eğrilikler görülmüştür.

Posterior spinal artrodezin elde edilmesi için uygulanması gereken prosedür standartize edilmiştir. Buna göre; subperiosteal disseksiyon, faset eksizyonu, dekortikasyon ve grefonaj dikkatli bir şekilde uygulanmalıdır. Enstrümantasyonun ilave edilmesinin amacı deformitenin düzeltilmesi ve füzyon oluşuna kadar internal tespitin sağlanmasıdır [1, 2, 12].

Skolyoz cerrahisinde kanama miktarı ameliyat, ameliyat süresine, seçilen girişim metoduna ve otojen kemik grefti kullanımına göre değişmektedir. Shapiro ve Shetna tarafından geniş bir literatür taraması şeklinde yapılan çalışmada, adölesan idiyopatik skolyoz cerrahisinde kan kaybı miktarının diğer skolyoz türlerinde göre daha düşük olduğu ve posterior enstrümantasyon esnasında pek çok yayında ortalama $750 \mathrm{cc}-1500 \mathrm{cc}$ arasında kan kaybı saptandığı bildirilmiştir [21]. Çalışmamızda ameliyat esnasında 250 cc-1000 cc arasında, ortalama 673 cc kan kaybının görüldüğü tespit edilmiştir.

Adölesan idiyopatik skolyozda, eğriliklerin frontal planda korreksiyonu üzerine yapılan çalışmalara bakıldığında; Cotrel-Dubousset sisteminde, fiksasyon için iki çeşit fiksasyon kullanılır; çengeller ve vidalar. Yıllar boyunca sadece çengellerle yapılan enstrümantasyon tedavide altın standart olarak kabul edilmiştir [22]. Lomber eğriliklerde distal bağlantı olarak pedikül vidalarından yararlanılmaya başlanmasıyla deformitelerde, deformite miktarı ve stabilizasyonun arttığı görülmüştür.

Hamil ve ark. [23] 1996 yılında distalde pedikül vidaları, proksimalde çengeller ile uyguladıkları hibrid sistemle ilgili çalışmalarını yayınlamışlardır. Çift majör veya King tip 4 eğriliği olan 44 hasta üzerinde yaptıkları bu çalışmada, lomber eğriliğin konveks tarafından pedikül vidası fiksasyonu ile hibrid estrümantasyon uygulanan hastaların Cobb açılarında, sadece çengel kullanılan gruba oranla, istatistiksel olarak anlamlı derecede daha fazla düzelme bildirmişlerdir. Enstümante edilen en alt vertebranın tiltinin ve translasyonununda daha iyi düzeldiğini bildirmişlerdir. Bunun sebebi, pedikül vidalarının, vertebranın üç kolonunda sağladığı yüksek tutunma kuvvetidir. Bu güçlü tutunma ile daha efektif olarak yapılan rot derotasyon manevrası ile koronal planda etkili bir şekilde düzelme elde edilirken, aynı zamanda sagital dizilimdede gelişme sağlanmıştır. Rot rotasyonunun düzelmeyi translasyonel kuvvetleri kullanarak sağladığı gösterilmiştir. Böylece lomber bölgeye yerleştirilen pedikül vidaları, bu translasyonel kuvvetlerin çok daha etkin kontrolüne izin verir.

Liljenqvist ve ark. ise 99 hasta içeren çalışmalarında, çengel ve hibrid enstrümantasyon 
uygulanan hastaların sonuçlarını karşılaştırdıklarında, post operatif erken dönemde iki grup arasında beligin bir fark tespit edememişlerdir. Bununla birlikte, uzun dönem takiplerinde (2-12 yıl), primer eğrilikteki düzelmenin vida grubunda istatiksel olarak anlamlı düzeyde daha fazla olduğunu ortaya koymuşlardır [24]. Adölesan idiyopatik skolyoz tedavisinde torasik pedikül vidalarının kullanımı ise 1995 yılında Suk ve ark. [25] tarafından tanımlanmıştır. Suk ve ark. 78 hasta üzerinde yaptıkları çalışmada, kullanılan enstrümantasyona göre, sadece çengel kullanılan grupta \%55 korreksiyon ve $\% 6$ korreksiyon kaybı tespit edilmiştir. Çengel paterninde vida kullanılan grupta \%66 korreksiyon ve $\% 2$ korreksiyon kaybı görülmüş, her seviyede pedikül vidası kullanılan grupta ise $\% 72$ korreksiyon ve \%1 korreksiyon kaybı bildirilmiştir.

Bizim çalışmamızda frontal planda major eğrilik değeri ortalama 47 derece olarak ölçülmüş, ameliyat sonrası ortalama \%61 düzelme ile postoperatif ortalama 19,4 derece tespit edilmiş, son kontrollerde ise ortalama \%9,6 korreksiyon kaybı görülmüştür.

Füzyona dahil edilen vertebra seviyelerine bakıldığında King tarafindan yapılan bir çalışmada füzyona katılan son vertebra seviyesi ile ameliyat sonrası gelişen bel ağrısı arasındaki ilişki incelenmiştir. Buna göre enstrümante edilen son vertebra L1 olduğunda $\% 25$ bel ağrısı görülmüş, L5 seviyesinin enstrümantasyona dahil edildiği olgularda ise, bel ağrıs $1 \% 82$ oranında tespit edilmiştir. Lomber bölgede füzyona katılan son vertebranın distalinde hiperlordoz gelişmesi, fasetlerin sıkışmasına ve disklerde erken dejenerasyonun ortaya çıkmasına neden olmakta, füzyon bölgesinin distalinde spinal darlık oluşmaktadır. Ameliyat sonrası ortaya çıkan ağrı şikayetinin azaltılabilmesi için, distalde mümkün olduğu kadar hareketli segment korumak önemlidir [26].

Çalışmamızda füzyona dahil edilen vertebralar; korreksiyon durumuna göre proksimalde T2 ile distalde L5 arasında olup, en uzun füzyon seviyesi T2, L4 arasında olmuştur. Füzyona dahil edilen vertebra seviyeleri 6 ile 14 seviye arasında değişmekle beraber ortalama 10,3 olarak bulunmuştur. Son enstrümante edilen vertebra seviyesi T12 ile L5 arasındadır. Adölesan idiyopatik skolyozun cerrahi tedavisi sonrasında en çok korkulan komplikasyon nörolojik defisit gelişmesidir. Nadir görülmekle beraber, hasta ve cerrah için büyük sıkıntı oluşturmaktadır. En sık nedeni farkedilmemiş spinal kord sıkışmasıdır. Ayrıca transpediküler vidaların kanal içine olan malpozisyonu, çengel ve rotların spinal kanala deplasmanı, aşırı düzeltmeye bağlı olarak spinal kord dolaşımının bozulması da nörolojik hasara neden olabilmektedir $[1,12]$

Nörolojik komplikasyonların önlenebilmesi amacı ile ameliyat esnasında Stagna'nın uyandırma testi uygulanmalı, sonucu pozitif ise derhal enstrümantasyon çıkarılmalıdır. Yapılan çalışmalarda gösterilmiştir ki, 6 saatten sonra nörolojik semptomların geri dönme şansı çok azalmaktadır [2,12]. Çalışmalarda nörolojik hasar oranları Harrington enstrümantasyon sisteminde \%0,23; sublaminar teller kullanıldığında \%0,86; CotrelDubousset enstrümantasyon sisteminde ise \%0,60 olarak bildirilmiştir. Adölesan idiyopatik skolyozun cerrahi tedavisi sonrası gelişen paralizi insidansı Skolyoz Araştırma Cemiyeti tarafından \%0,26 olarak bildirilmiştir $[2,12]$. Bizim çalışmamıza dahil edilen olgularda, ameliyat sonrası herhangi bir nörolojik hasar tespit edilmemiştir.

Puno, Lenke ve ark. [27], adölesan idiyopatik skolyoz cerrahisi sonrasında görülen nörolojik olmayan komplikasyonların prevalansını incelemişler, çeşitli yayınlarda $\% 0$ ile \%10 arasında değişen oranlarda bildirmiş olmasına rağmen, bu yayınların retrospektif olduğunu ve komplikasyonlardan çok, tedaviyi değerlendirme amacinda olduğunu belirtmişlerdir. Kendi çalışmalarında \%15,4 oranında nörolojik olmayan komplikasyon tespit etmişlerdir. Ameliyat ve anestezi süresinin uzaması ve kan kaybının fazla olması, renal hastalık öyküsü varlığının komplikasyon oranını belirgin olarak arttırdığını da belirtmişlerdir.

Çalışmamızda ameliyat sonrası hiçbir olguda yüzeyel yada derin yara yeri enfeksiyonu tespit edilmemiştir. Olguların hiçbirinde psödoartroz saptanmamıştır. Ayrıca hiçbir olguda revizyon cerrahisi gerekmemiştir. 


\section{Kaynaklar}

1. Herring JA. Tachdjian's Pediatric Orthopaedics. 3rd Edition, New York: W. B. Saunders Company.2002; 213-99.

2. Freeman BL. Scoliosis and Kyphosis. Canale S.T. Campbell's Operative Orthopaedics, 10th Edition. Mosby, Philadelphia 2003; Volume 2; 1751-1837.

3. Mehlman CT. Idiopathic Scoliosis, Emedicine from WebMD, Http://www.emedicine.com/orthoped/topic504.htm 2004.

4. Mohan AL, Das K. History of surgery for the correction of spinal deformity. Neurosurg Focus 2003; 14(1):1-5.

5. Lowenstein JE. Idiopathic Scoliosis. MOE'S Textbook of Scoliosis and Other Spinal Deformities. 3rd Edition, Philadelphia: W.B Saunders Company 1995; 219-56.

6. Dormans JP. Pediatric Orthopaedics: Core Knowledge in Orthopaedics. 1st Edition. Elsevier Mosby, Philadelphia 2005; 265-78.

7. Bono CM, Garfin SR. Spine: Orthopaedic Surgery Essentials, Lippincott Williams \&Wilkins, Philadelphia 2004; 163-74.

8. Bridwell KH. Surgical treatment of idiopathic adolescent scoliosis. Spine 1999; 24: 2607-16.

9. Kostuik JP. Current concepts review operative treatment of idiopathic scoliosis. J Bone Joint Surg 1990; 72: 1108-12.

10. Foster MR. A functional classification of spinal instrumentation. Spine J 2005; 5: 682-94.

11. Gögüş A, Akman Ş, Talu U, Şar C, Hamzaoğlu A. Adölesan idiyopatik skolyozun anterior enstrumentasyon ile tedavisi ve erken sonuçlar. Acta Orthop Traumatol Turc 2001; 35: 196-207.

12. Winter RB, Denis F, Lonstein JE, Garemella J. Techniques of surgery. MOE'S Textbook of Scoliosis and Other Spinal Deformities. 3rd Edition, Philadelphia: WB Saunders Company 1995; 133-217.

13. Kaneda K, Shuno Y, Satoh S, Abumi K. Anterior correction of thorasic scoliosis with Kaneda anterior spinal system. A preliminary report. Spine 1997; 15: 22: 1358-68.

14. Parsch D, Geartner V, Brocai DRC, Carstens C. The effect of spinal fusion on the long-term outcome of idiopthic scoliosis. J Bone Joint Surg 2003; 1133-6.

15. Lee CS, Nachemson AL. The crankshaft phenomenon after posterior Harrington fusion in skeletally immature patients with thoracic or thoracolomber idiopathic scoliosis followed to maturity. Spine 1997; 22: 58.

16. Dubousset J, Herring JA, Shufflebarger H. The crankshaft phenomenon. J Pediatr Orthop 1989; 9: 541.

17. Bjerkreim I. Steen H. Brox JI. Idiopathic scoliosis treated with Cotrel-Dubousset instrumentation: Evaluation 10 years after surgery. Spine 2007; 32: 2103-10.

18. Sucato DJ, Hadequist D, Karol LA. Operative Correction of Adolescent Idiopathic Scoliosis in Male Patients. J Bone Joint Surg 2004; 86: 2005-14.

19. Benli T, Ateş B. Akalın S 10 years follow-up surgical results of adolescent 1diopathic scoliosis located with TSRH instrumentation. Eur. Spine J 2005; 14 : 298-326.

20. Roye DP, Farcy JP, Rickert JB, Godfried D. Results of spinal instrumentation of adolescent idiopathic scoliosis by King type. Spine 1992; 17: 270-3.

21. Shapiro F, Sethna N. Blood loss in pediatric spine surgery. Eur Spine J. 2004; 1: 6-17.

22. Lowenstein JE, Matsumoto H, Vitale MG, Weidenbaum M. Coronal and sagittal plane correction in adolescent idiopathic scoliosis: A comparison between all pedicle screw versus hybrid thoracic hook lumbar screw constructs. Spine 2007; 32: 448-52.

23. Hamill CL, Lenke LG, Bridwell KH, Chapman MP, Blanke K, Baldus C. The use of pedicle screw fixation to improve correction in the lumbar spine of patients 
with idiopathic scoliosis. Is it warranted? Spine 1996; 21: 1241-9.

24. Liljenqvist U, Lepsien U, Hackenberg L, Niemeyer T, Halm H. Comparative analysis of pedicle screw and hook instrumentation in posterior correction and fusion of idiopathic thoracic scoliosis. Euro Spine J 2002; 11: 336-43.

25. Suk SI, Lee CK, Kim WJ, Chung YJ, Park YB. Segmental pedicle screw fixation in the treatment of thoracic idiopathic scoliosis. Spine 1995; 20: 1399-405.

26. Rinella A, Bridwell K, Kim Y, Rudzki J, Edwards C, Roh M, Lenke LG, Berra A. Late complications of adult idiopathic scoliosis primary fusion L4 and above: the effect of age and distal fusion level. Spine 2004; 29: 318-25.

27. Puno R, Lenke L, Richards S. Non-neurologic complications following surgery for adolescent idiopathic scoliosis. J Bone Joint Surg 2007; 89: 2427-32. 